\title{
'Determinism' is Just Fine: A Reply to Scott Sehon
}

Scott Sehon has recently argued that the notion of determinism employed in the Consequence Argument is such that, if our world turns out to be deterministic in this way, then an interventionist God is logically impossible. He further argues that because of this, we should revise our notion of determinism. However, this notion of determinism is prevalent in the free will literature, ${ }^{1}$ and a rejection of it would have a much larger impact than merely giving us grounds to reject the Consequence Argument. In this paper I show that Sehon's argument for the claim that the truth of determinism, in this sense, would make an interventionist God logically impossible ultimately fails. I then offer and respond to a weaker version of the argument for the claim that we should revise our notion of determinism. Finally, I develop and respond to a possible worry for my argument

\section{Sehon's Arguments}

The notion of determinism that Sehon argues against was outlined by van Inwagen (1983). On van Inwagen's account, the following is true in a deterministic universe:

For every instant of time, there is a proposition that expresses the state of the world at that instant.

If $p$ and $q$ are any propositions that express the state of the world at some instants, then the conjunction of $p$ with the laws of nature entails $q$ (1983: 65).

${ }^{1}$ For some examples see: Watson (2003: 2), Kane (2011: 4), and Vargas in Fischer et al. (2007: 2). 
If a world is deterministic in this way, then "given the past and the laws of nature, there is only one possible future" (1983: 65). ${ }^{2}$ This is a feature of the standard notion of determinism that van Inwagen attempts to capture when he tells us that the following sentence would be true if our world were deterministic: $\square\left(\left(\mathrm{P}_{0} \& \mathrm{~L}\right) \supset \mathrm{P}\right)$, where " $\mathrm{P}_{0}$ " stands for a sentence expressing a proposition expressing the state of the actual world in the remotely distant past. For the purposes of this paper, however, we can have it so that " $\mathrm{P}_{0}$ " stands for a sentence expressing a proposition expressing the state of the world at a time very close to the beginning of the universe. "L" stands for a sentence providing a statement of the laws of nature of the actual world, and "P" is a dummy for which we can substitute any true proposition (1983: 94). In other words, if our world were deterministic, $\square\left(\left(\mathrm{P}_{0} \& \mathrm{~L}\right) \supset \mathrm{P}\right)$ would be true for any $\mathrm{P}$ which is true in the actual world. ${ }^{3}$ Henceforth, I refer to this notion of determinism as the "strict implication notion of determinism”. When I say that a world is SI deterministic, I mean that it is deterministic in this way.

The other notion we need is that of an interventionist God:

On a fairly traditional conception of God, God has the ability to intervene in the natural order ... in other words, necessarily if an interventionist God does exist, then it is possible that the same initial state of affairs obtains, along with the same laws of nature, and yet $\mathrm{P}$ is false (Sehon 2011: 32).

Let us take it for granted that this provides an adequate conception of an interventionist God.

Suppose that there is an interventionist God in world w1. On this conception of an interventionist God, since the God in w1 is interventionist, there must be some other world, w2, with the same

\footnotetext{
${ }^{2} \mathrm{~A}$ similar version of this thesis is sometimes stated differently: if a world is deterministic, then given the past and the laws, there is only one physically possible future. For the purposes of this paper, this difference is not relevant. Generally, when people talk about an interventionist God, they are thinking of a God that can either intervene directly in the physical world, or indirectly, by way of intervening with things that can in turn interact with the physical world. If an interventionist God could make it such that future events are not determined, then a world with such a God would not have only one physically possible future either.

${ }^{3}$ Some allow for indeterministically caused events at the beginning of the universe. If this is so, this necessary conditional would hold for any $\mathrm{P}$ after $\mathrm{P}_{0}$, where $\mathrm{P}_{0}$ is just after the beginning of that universe.
} 
initial state of affairs as $\mathrm{w} 1$, and the same laws as $\mathrm{w} 1$, in which some $\mathrm{P}$ (which was true in w1) is false in w2. Sehon is appealing to Swinburne's notion of an interventionist God, which can intervene in one of two ways: "[a] divine intervention will consist either in God acting in areas where natural laws do not determine what happens ... or in God temporarily suspending the natural laws” (Swinburne 1996: 116). The sort of God that we are interested in here is one that can suspend the laws of nature. Hereafter, when I talk of interventions, I will mean interventions of this sort.

Using these notions, Sehon offers the following argument:

[N]ecessarily, if an interventionist God does exist, then it is possible that the same initial state of affairs obtains, along with the same laws of nature, and yet $\mathrm{P}$ is false - i.e. it is possible that $\mathrm{P}_{0} \& \mathrm{~L} \& \sim \mathrm{P}$. Even if God does not exist and determinism is true, surely it is at least possible that an interventionist God exists, and thus it will be possible that $\mathrm{P}_{0} \& \mathrm{~L} \& \sim \mathrm{P}$. But since $\mathrm{P}_{0} \& \mathrm{~L} \& \sim \mathrm{P}$ is equivalent to $\sim\left(\mathrm{P}_{0} \& \mathrm{~L} \supset \mathrm{P}\right)$, it follows that $\square\left(\mathrm{P}_{0} \& \mathrm{~L} \supset \mathrm{P}\right)$ is not true, even if determinism is true (Sehon 2011: 31).

A formal version of the argument, where "IG" stands for 'an interventionist God exists', is also provided (2011: 32):

$$
\begin{aligned}
& \square\left(\mathrm{IG} \supset \diamond\left(\mathrm{P}_{0} \& L \& \sim \mathrm{P}\right)\right) \\
& \diamond \mathrm{IG} \\
& \therefore \diamond\left(\mathrm{P}_{0} \& \mathrm{~L} \& \sim \mathrm{P}\right) \\
& \therefore \sim \square\left(\left(\mathrm{P}_{0} \& \mathrm{~L}\right) \supset \mathrm{P}\right)
\end{aligned}
$$

Premise 1 tells us that necessarily, if an interventionist God exists, then it is possible that in a world with the same past and laws as ours, $\mathrm{P}$ is not true (whereas it is in the actual world). Given the assumption that an interventionist God is at least possible, we can then show that there is a world with the same past and laws as the actual world where P is not true. From this we can prove that $\square\left(\left(\mathrm{P}_{0} \& \mathrm{~L}\right) \supset \mathrm{P}\right)$ is false, since a statement of the past and the laws does not entail $\mathrm{P}$. 
If we present this argument from the other direction, then we can show how "the truth of determinism, on van Inwagen's conception, would make the existence of an interventionist God a logical impossibility” (Sehon 2011: 32). A formal version of this argument is given:

$$
\begin{aligned}
& \square\left(\left(\mathrm{P}_{0} \& \mathrm{~L}\right) \supset \mathrm{P}\right) \\
& \square\left(\mathrm{IG \supset} \diamond\left(\mathrm{P}_{0} \& \mathrm{~L} \& \sim \mathrm{P}\right)\right) \\
& \therefore \sim \diamond \mathrm{IG}
\end{aligned}
$$

Premise 1 is the sentence that would be true if our world were SI deterministic, and premise 2 is the same as premise 1 from the argument above. Let us call this argument the "Impossibility Argument” since it argues that, if SI determinism were the case, then an interventionist God would be logically impossible.

If the Impossibility Argument is successful, then as long as we wish to hold that an interventionist God is possible and that a deterministic world is possible, we should revise our understanding of determinism. Let us call this the "Revision Argument”, since it argues for a revision of our concept of determinism.

\section{Against the Impossibility Argument}

Although the Impossibility Argument is valid, one might think that, since our world seems to be indeterministic, it is unsound because premise 1 is false. I will argue that, even if the first premise were true, the argument would still be unsound due to the falsity of the second premise, which does not adequately capture what an interventionist God could do. The existence of an interventionist God would only tell us something about other worlds with the same past and laws as the world in which this God exists. When we pick out a world where an interventionist God exists and a P which is true in that world, there is another world with the same past and laws as 
the original world that we picked out in which $\mathrm{P}$ is false. This would not tell us whether a statement of a different set of past and laws would entail a statement about the future.

In order to clarify my point, I will introduce an extension to the notation used so far. To "P" and "L", I will add subscripts that name a world, and the sentence which has this subscript will be a sentence that is true in that world. For example, in the original argument, "L" was an abbreviation for a sentence stating the laws of nature of the actual world. Employing the new notation, “L@” will stand for a sentence stating the laws of nature that hold in the actual world. To be clear, $\mathrm{L} @$ is true in some other possible worlds: worlds in which $\mathrm{L} @$ is true have the same laws of nature as the actual world; "L@” does not pick out a world, it merely picks out a specific

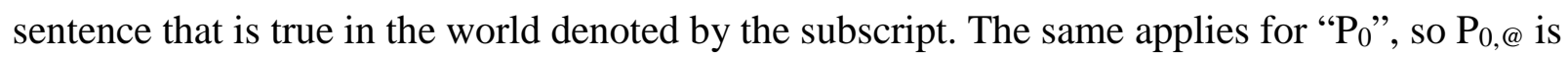
true in other worlds which have the same initial state of affairs as the actual world.

Now consider w1, a world where there is an interventionist God, and suppose P is true in w1. " $\mathrm{L}_{\mathrm{w} 1}$ " will stand for a sentence stating the laws of nature of $\mathrm{w} 1$, and " $\mathrm{P}_{0, \mathrm{w} 1}$ " will stand for a sentence expressing a proposition expressing the state of $\mathrm{w} 1$ at a time very close to the beginning of that universe. We can then suppose that there is another possible world, w2, which has the same laws and past as w1 (i.e., both $\mathrm{L}_{\mathrm{w} 1}$ and $\mathrm{P}_{0, \mathrm{w} 1}$ are true in $\mathrm{w} 2$ ), yet $\mathrm{P}$ is not true in $\mathrm{w} 2$. The falsity of P in w2 is due to the God's intervention, which prevented it from being true. Surely, if this is the case then a statement of the past and the laws of w1 does not entail P, for we have two worlds with that past and set of laws that differ on the truth of $\mathrm{P}$. That is, since $\mathrm{L}_{\mathrm{w} 1}$ and $\mathrm{P}_{0, \mathrm{w} 1}$ are true in both w1 and w2, but $\mathrm{P}$ is true in one but not the other, $\square\left(\left(\mathrm{P}_{0, \mathrm{w} 1} \& \mathrm{~L}_{\mathrm{w} 1}\right) \supset \mathrm{P}\right)$ comes out false. From this we could conclude that neither w1 nor w2 are SI deterministic. However, although we know that a statement of the past and the laws of $\mathrm{w} 1$ do not entail $\mathrm{P}$, this does not help us know whether this is true for statements of other, different, sets of pasts and laws. 
Now further suppose that the actual world is SI deterministic, making $\square\left(\left(\mathrm{P}_{\left.\left.0, @ \& \mathrm{~L}_{@}\right) \supset \mathrm{P}\right)}\right.\right.$ true. If a statement of the actual past and the laws entails $\mathrm{P}$, then we know that an interventionist God could not make P false in a world with the same past and laws (a world where $\mathrm{P}_{0, @}$ and $\mathrm{L}_{@}$ are true). We would also know that either $\mathrm{P}_{0, @}, \mathrm{~L}_{@}$, or both, are false in both w1 and w2, since a statement of the past and laws of those worlds is consistent with the truth or falsity of P. This, though, would not show us that w1 and w2 are not possible worlds, as long as the laws and the past are contingent matters. Nor does the possibility of w1 and w2 make $\square\left(\left(\mathrm{P}_{0, @ \& L} \&\right) \supset \mathrm{P}\right)$ false,

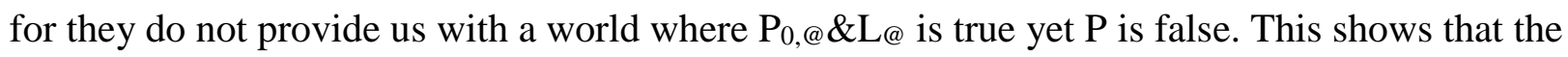
assumption that the actual world is SI deterministic, when joined with the claim that there is a possible world (w1) with an interventionist God of the relevant sort, does not result in a contradiction.

Where does the Impossibility Argument go wrong, then? I suggest that it goes wrong in the symbolization provided for premise 2 , which states that $\square\left(\mathrm{IG \supset} \diamond\left(\mathrm{P}_{0} \& L \& \sim \mathrm{P}\right)\right)$. To show this, let us employ the notation introduced to express Sehon’s argument:

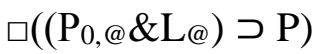

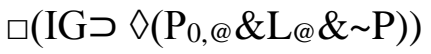

$$
\begin{aligned}
& \therefore \sim \gg \mathrm{IG}
\end{aligned}
$$

The first premise states the characteristic sentence that would be true if the actual world were deterministic. The second premise states that, necessarily, if an interventionist God exists, then there is a possible world with the same past and laws as the actual world where P does not occur. The interventionist God we were considering was the type of being that could suspend the laws of nature of the world in which the God exists. If a possible world has an interventionist God, then there is some true $\mathrm{P}$ in that world which is false in another world with the same past and laws. The symbolization provided for premise 2 makes the leap from this to the claim that there 
is a world with the same past and laws as the actual world where $\mathrm{P}$ is false. We have not been given reason to suppose that an interventionist God in a world with different laws than the actual one could suspend the laws of the actual world.

There certainly is a contradiction in thinking that SI determinism and an interventionist God are compossible. A statement of the past and the laws of nature in a world with such a God would not entail a statement about the future, since there will be possible worlds with the same past and laws in which God intervenes and there is a different future. Although an interventionist God and SI determinism are not compossible, there is still no contradiction in supposing that they are both possible, for SI determinism in one world does not imply something about what a statement of a different set of past and laws entails. Because of this, the Impossibility Argument fails.

\section{Against the Revision Argument}

The Revision Argument was intended to show that we should revise our notion of determinism i.e., we should steer away from the strict implication version of it. This was based on the claim that if we keep the strict implication notion of determinism and we want to allow for the possibility of our world's being deterministic, then we would have to reject the logical possibility of an interventionist God. We have seen that the Impossibility Argument fails, thereby undermining the main motivation for the Revision Argument.

There may, however, be a weaker version of the Revision Argument available. An interventionist God is incompatible with SI determinism, so if we want to hold that there is a deterministic world with an interventionist God, we should revise our notion of determinism. This argument is weaker because the claim that there is a deterministic universe with an 
interventionist God is less plausible than the claim that an interventionist God is possible. In a world where God can intervene and change the course of events but is not himself determined to do so, we would not be able to say that there is only one possible future, given the past and the laws.

Sehon does not offer a revision of 'determinism', but he does offer a sufficient condition for a world's being indeterministic: ${ }^{4}$

Consider the cup of coffee I was holding in my left hand as I contemplated this sentence. We assume that our laws of nature are such that, had I simply let go of it, it would have fallen. Once we recognize that it is logically possible that God could have made the cup float rather than fall, then it is a very short step to recognizing the mere logical possibility that the laws of nature could have been suspended for any reason, with or without God or demons. Of course, if the laws of nature are suspended for my coffee cup, whether by God or for no reason at all, then our universe turns out not to be deterministic (2011: 34 [italics added]).

Sehon's point here is that even if this world is deterministic, and the cup of coffee does not float,

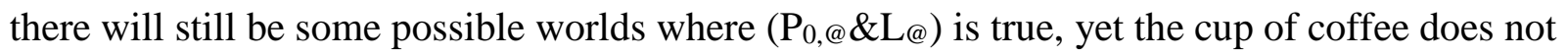
fall, and, more specifically, one of those worlds will not include an interventionist God. There are a few worries about the plausibility of this situation. First, it is not clear what it would mean to say that the laws of nature are such that, if he had let go of the cup, it would have fallen; this is especially unclear if we are to suppose that there are worlds with the same laws where the cup does not fall. Furthermore, it is not clear what it would mean to say that the laws of nature are suspended for no reason whatsoever. What is important for our purposes here is the last sentence of the passage, which tells us that if the laws of nature are suspended in a world, then that world is indeterministic.

Suppose we revise our notion of determinism, such that, whatever else the revision involves, it stipulates that if there is a suspension of the laws, then the world is not deterministic.

\footnotetext{
${ }^{4}$ As I am using "indeterministic" here, a world is indeterministic just in case it is not deterministic. I take determinism and indeterminism to be mutually exclusive and jointly exhaustive.
} 
On this notion of determinism, if a God intervenes, then the world is not deterministic, so at best, this notion would allow for deterministic worlds where an interventionist God does not intervene. Now we might weigh our options when it comes to deciding whether we should revise our notion of determinism. If we revise it, yet hold this condition, then we get deterministic worlds with interventionist Gods, although we don't get any deterministic worlds where these Gods intervene. On both this revised version and the strict implication version, we know that if our world turns out to be deterministic, then if there is a God, he does not intervene. The cost of accepting the strict implication notion of determinism, at least when it comes to modal claims about an interventionist God, is very similar to the cost incurred by revising the notion in a way that fits Sehon's condition. If the Revision Argument is supposed to rely on the plausibility of the claim that, "there are worlds that are deterministic and there are worlds with an interventionist God”, then this comes out true on both versions of 'determinism'. If, on the other hand, the argument relies on the plausibility of the claim that, "there are deterministic worlds in which God intervenes”, then both notions fail equally.

\section{An Objection}

A possible objection to my argument is that the model provided in section 2 does not allow for an adequate response to the Impossibility Argument. ${ }^{5}$ I will drop talk of the actual world and merely appeal to world w3 for an example of an SI deterministic world in this section. The model provided in section 2 assumed that there could be a world such as w3 that was SI deterministic. Since we are supposing that w3 is SI deterministic, $\square\left(\left(\mathrm{P}_{0, \mathrm{w} 3} \& \mathrm{~L}_{\mathrm{w} 3}\right) \supset \mathrm{P}\right)$ would be true for any $\mathrm{P}$ which is true in w3. Now recall worlds w1 and w2 from section 2 . These worlds had an interventionist God and they had the same past and laws as each other $\left(\mathrm{P}_{0, \mathrm{w} 1} \& \mathrm{~L}_{\mathrm{w} 1}\right.$ is true

\footnotetext{
${ }^{5}$ I would like to thank an anonymous reviewer for suggesting this objection.
} 
in both), yet there was a $\mathrm{P}$ which was true in w1 but false in w2, and it was false in w2 in virtue of the God's intervention. In the model provided in section 2, there would be no contradiction in supposing that all three of these worlds are possible; but perhaps this is mistaken. Since we are supposing that w3 is SI deterministic, and hence that $\square\left(\left(\mathrm{P}_{0, w 3} \& \mathrm{~L}_{\mathrm{w} 3}\right) \supset \mathrm{P}\right)$ is true, we are forced to conclude that the interventionist Gods in worlds w1 and w2 could not have made it the case that $\mathrm{P}_{0, \mathrm{w} 3} \& \mathrm{~L}_{\mathrm{w} 3} \& \sim \mathrm{P}$.

One might worry that there is something wrong with this picture. There may be another sort of God which we have not considered, an omnipotent interventionist God. The possibility of this sort of God could spell trouble for my argument, since this possible God could make a world where $\mathrm{P}_{0, \mathrm{w} 3} \& \mathrm{~L}_{\mathrm{w} 3} \& \sim \mathrm{P}$ is true, since this God is omnipotent. If this is right, then a version of the Impossibility Argument which replaced "IG", the claim that an interventionist God exists, with “OIG”, the claim that an omnipotent interventionist God exists, would avoid the problem posed in section 2 .

There are, I think, a few things that could be said in response to this worry. The notion of 'omnipotence' is quite difficult to work out; but presumably, there is some notion of it which a possible being may have. First, it will be helpful to note that there could be such an omnipotent God of which statements of the form "This God cannot A" are true. For example, an omnipotent God could not make it the case that $2+2=5$, or that a square circle exists. Even though a God may be omnipotent, this God will not be able to do just anything. ${ }^{6}$

Now suppose that " $\mathrm{P}_{0, w 3}$ " expresses the state of $\mathrm{w} 3$ at its beginning, and included in $\mathrm{P}_{0, \mathrm{w} 3}$ is the claim that there is no God, and the laws stated in $\mathrm{L}_{\mathrm{w} 3}$ are such that they don't allow for the creation of another God. This means that $\mathrm{P}_{0, \mathrm{w} 3} \& \mathrm{OIG}$ would be contradictory, since it would

\footnotetext{
${ }^{6}$ For discussion of this, and references to others who consider this, see Plantinga 1974 and Swinburne 1977 (esp. Ch. 9).
} 
include OIG and a claim which entails $~ O I G$. In a world where $\mathrm{P}_{0, \mathrm{w} 3} \&_{\mathrm{w} 3}$ is true, OIG must be false. Just like an omnipotent God cannot create a square circle, an omnipotent God does not exist in a world where there is no God. Whatever the right notion of omnipotence turns out to be, a God that has this property still won't be able to exist in a world where there is no God. Suppose that w4 has an omnipotent interventionist God. What we could conclude is that $\mathrm{P}_{0, \mathrm{w} 3} \& \mathrm{~L}_{\mathrm{w} 3}$ comes out false in w4. On this model, the truth of $\square\left(\left(\mathrm{P}_{0, \mathrm{w} 3} \& \mathrm{~L}_{\mathrm{w} 3}\right) \supset \mathrm{P}\right)$ would be consistent with the possibility of an omnipotent interventionist God, even though the truth of $\mathrm{P}_{0, \mathrm{w} 3} \& \mathrm{~L}_{\mathrm{w} 3}$ at a world would entail that there is no God in that world.

There are two further points that I would like to make to perhaps further mitigate the worry. First, notice that although $\square\left(\left(\mathrm{P}_{0, \mathrm{w} 3} \& \mathrm{~L}_{\mathrm{w} 3}\right) \supset \mathrm{P}\right)$ would be true on the model just presented, and that this is consistent with the possible existence of some very powerful being, the model presented does not imply that this God could not suspend any of the laws expressed by $\mathrm{L}_{\mathrm{w} 3}$. That is, although the past and laws of w3 may allow for only one possible future, this does not mean that all worlds in which $\mathrm{L}_{\mathrm{w} 3}$ is true have only one possible future. Suppose $\mathrm{P}_{0, \mathrm{w} 4}$ includes the claim that there is an omnipotent interventionist God. If there is a world where $\mathrm{P}_{0, \mathrm{w} 4} \& \mathrm{~L}_{\mathrm{w} 3}$ is true, it may be that $\square\left(\left(\mathrm{P}_{0, w 4} \& \mathrm{~L}_{\mathrm{w} 3}\right) \supset \mathrm{P}\right)$ turns out to be false, because a God may intervene to make it such that $\sim \mathrm{P}$. This is perfectly consistent with the truth of $\square\left(\left(\mathrm{P}_{0, \mathrm{w} 3} \& \mathrm{~L}_{\mathrm{w} 3}\right) \supset \mathrm{P}\right)$. Although this God may not be able to make it such that $\mathrm{P}_{0, \mathrm{w} 3} \& \mathrm{~L}_{\mathrm{w} 3} \& \sim \mathrm{P}$ is true, this God may still be able to intervene in a world with the same laws. This God's powers would not be so oddly circumscribed.

It is worthwhile to reiterate a point alluded to earlier that applies here as well. What seems to be a crucial component of determinism is that in a deterministic world, there is only one possible future given the past and laws. Perhaps there are other ways of capturing this than the 
notion of SI determinism provides, but if we insist that there are no possible sets of states of affairs joined with laws of nature that a God could not produce and later intervene in, then having a world with one possible future, given the past and the laws, will be impossible to achieve. We will lose not only the possibility of an SI deterministic world, but also the possibility of a deterministic world in general. This, I think, would make a revision argument much harder to accept.

\section{Conclusion}

In this paper I have shown that the truth of determinism in the strict implication sense does not entail that an interventionist God is impossible, and so, contra Sehon, this is not reason to revise our concept of determinism. Perhaps the strict implication notion of determinism faces some problems, and perhaps there is a revision that can avoid these, but Sehon has given us neither a revised notion nor a successful argument for the claim that the strict implication notion faces a problem. ${ }^{7}$ Even if we wanted to have a notion of determinism that allows for a God's intervening in a deterministic universe, this would force us to give up what seems to be a crucial component of the notion of determinism, namely that there is only one possible future given the past and the laws. $^{8}$

\section{References}

Fischer, J., Kane, R., Pereboom, D., and Vargas, M. (2007). Four Views on Free Will. Malden, MA: Blackwell.

\footnotetext{
${ }^{7}$ Mackie offers a revision of the SI notion of determinism on which we add to the antecedent of the characteristic sentence a conjunct stating that nothing supernatural interferes with the natural order (1982: 19-20). This revision as well would force us to reject the claim that there is only one possible future, given the past and the laws. Thanks to $n . n$. for bringing this revision to my attention.

${ }^{8}$ ACKNOWLEDGMENTS
} 
Kane, R. (ed.) 2011. The Oxford Handbook of Free Will. Oxford: Oxford University Press.

Mackie, J.L. 1982. The Miracle of Theism. Oxford: Oxford University Press.

Plantinga, A. 1974. God, Freedom, and Evil. Wm. B. Eerdmans Publishing

Sehon, S. 2011. A Flawed Conception of Determinism in the Consequence Argument. Analysis 71: 30-38.

Sehon, S. 2012. "Action Explanation and the Free Will Debate: How Incompatibilist Arguments Go Wrong.” Philosophical Issues 22: 351-368.

Swinburne, R. 1977. The Coherence of Theism. Oxford: Oxford University Press.

Swinburne, R. 1996. Is There a God? Oxford: Oxford University Press.

van Inwagen, P. 1983. An Essay on Free Will. Oxford: Clarendon Press.

Watson, G. (ed.) 2003. Free Will. Oxford: Oxford University Press. 